ARCHIVO ESPAÑOL DE ARTE, XCIII, 371

JULIO-SEPTIEMBRE 2020, pp. 301-306

ISSN: 0004-0428, eISSN: 1988-8511

https://doi.org/10.3989/aearte.2020.20

\title{
ALONSO CANO PINTOR DE MITOLOGÍAS: EL BACO \\ DE LA REAL ACADEMIA DE BELLAS ARTES DE SAN FERNANDO Y UN DIBUJO EN LA BIBLIOTECA NACIONAL DE ESPAÑA*
}

\author{
Benito Navarrete Prieto ${ }^{1}$ \\ Universidad de Alcalá
}

\begin{abstract}
El presente artículo pretende atribuir a Alonso Cano la pintura de un Baco procedente de la colección de Godoy y conservada en la Real Academia de Bellas Artes de San Fernando. Se estudia además su proceso creativo en relación a un dibujo localizado en la Biblioteca Nacional de España entre los italianos del siglo XVI, y que creemos es característico del pintor granadino y relacionado con la gestación de esta obra.
\end{abstract}

Palabras clave: Alonso Cano; dibujo; barroco; tradición clásica.

\section{ALONSO CANO PAINTER OF MYTHOLOGIES: THE BACCHUS FROM THE REAL ACADEMIA DE BELLAS ARTES DE SAN FERNANDO AND A DRAWING LOCATED IN THE BIBLIOTECA NACIONAL DE ESPAÑA}

This article attempts to attribute to Alonso Cano the painting of a Bacchus from the Godoy collection and preserved in the Real Academia de Bellas Artes de San Fernando. His creative process is also studied in relation to a drawing located in the Biblioteca Nacional de España among the Italians drawings of the 16th century and that the present author believes is characteristic of the Granada-born painter and related to the gestation of this painting.

Key words: Alonso Cano; drawing; baroque; classical tradition.

Cómo citar este artículo / Citation: Navarrete Prieto, Benito (2020): "Alonso Cano pintor de mitologías: el Baco de la Real Academia de Bellas Artes de San Fernando y un dibujo en la Biblioteca Nacional de España”. En: Archivo Español de Arte, vol. 93, núm. 371, Madrid, pp. 301-306. https://doi.org/10.3989/aearte.2020.20.

Hace unos años la investigadora Itziar Arana ${ }^{2}$ daba a conocer un lienzo de un Baco conservada en los depósitos de la Real Academia de Bellas Artes de San Fernando donde ingresó en 1816 procedente del secuestro de la colección de Godoy del Palacio de Buenavista. La pintura ${ }^{3}$ llegaba con una atribución al estilo de Tiziano según el inventario de la colección realizado por Frédéric Quilliet en $1808^{4}$. Durante el proceso de restauración llevado a cabo en la RABASF, al

* Este artículo es fruto del proyecto de investigación Dibujo italiano y español del siglo XVI de la Biblioteca Nacional de España HAR2017-86804-P del MINECO programa estatal de fomento de la investigación científica y técnica de excelencia, subprograma estatal de generación de conocimiento.

1 benito.navarrete@uah.es /ORCID iD: https://orcid.org/0000-0002-7966-9166.

2 Arana, 2014: 134-135.

3 Óleo sobre lienzo, 168 x $110 \mathrm{~cm}$. Real Academia de Bellas Artes de San Fernando. № inv. 0413 Agradezco a Itziar Arana la fotografía de la obra y el acceso a la pintura para su estudio en la Real Academia de Bellas Artes de San Fernando.

${ }^{4}$ Inventariado como "Baco reclinado" con el no 643. En el inventario de 1808 aparece como escuela de Tiziano, en el de 1813 se ignora su autor y en el de 1814/15 aparece descrito como "Baco tendido con una copa en la mano, 


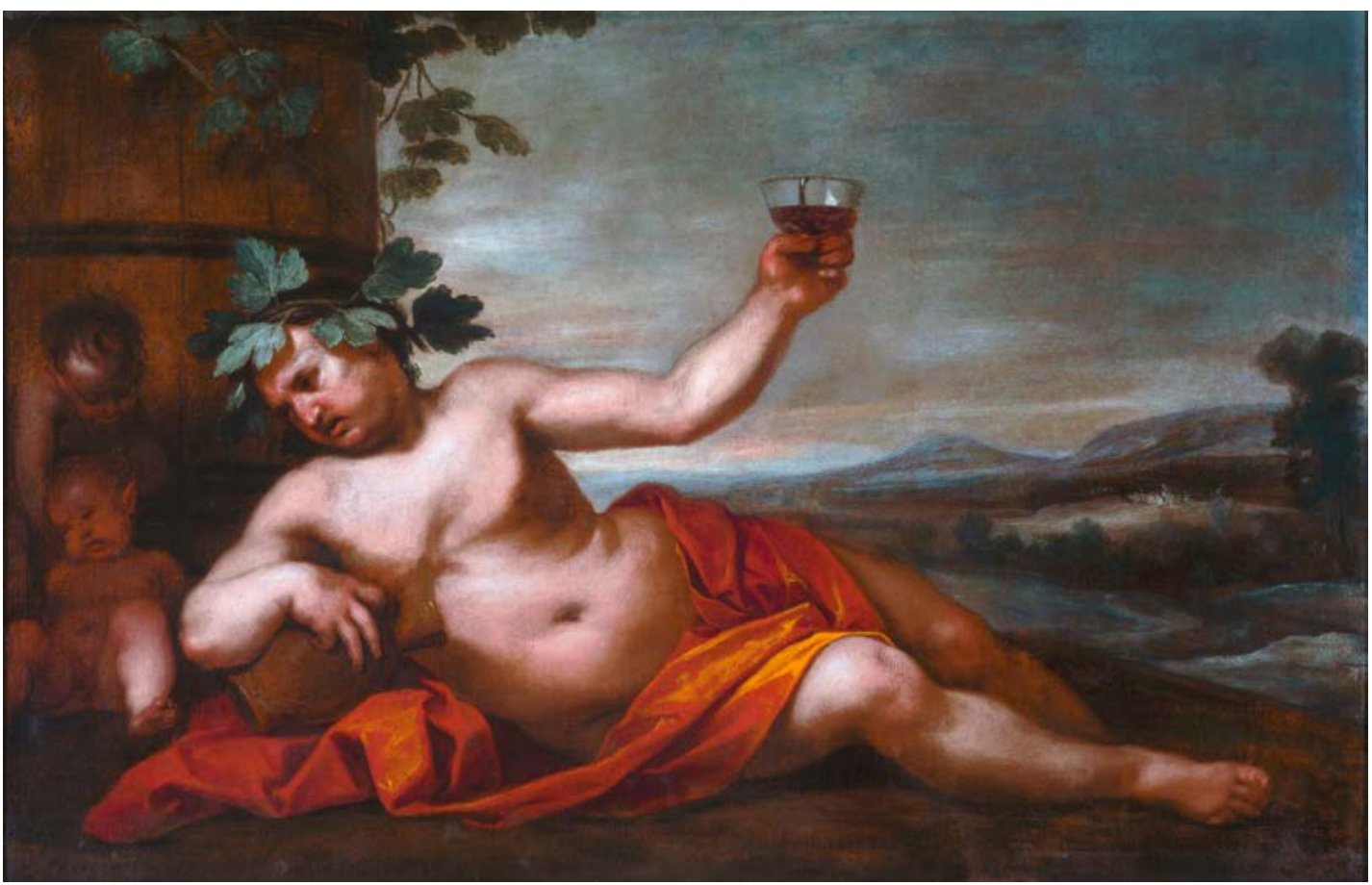

Fig. 1. Alonso Cano (aquí atribuido), Baco reclinado (1645-1650). Real Academia de Bellas Artes de San Fernando.

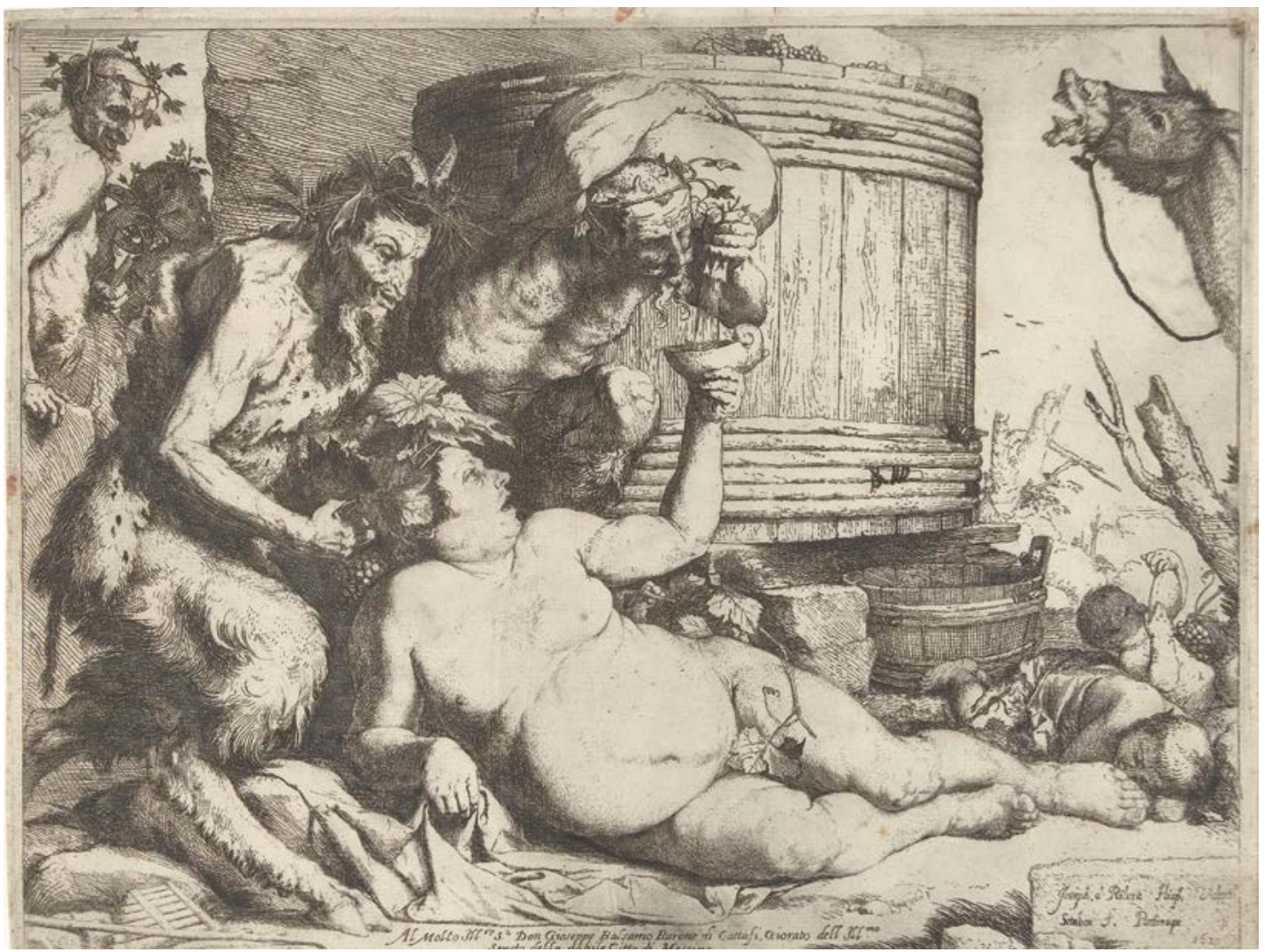

Fig. 2. José de Ribera, Sileno ebrio (1628). Ámsterdam, Rijksmuseum.

Archivo Español de Arte, vol. XCIII, n. ${ }^{\circ}$ 371, pp. 301-306, julio-septiembre 2020 ISSN: 0004-0428, eISSN: 1988-8511, https://doi.org/10.3989/aearte.2020.20 
eliminar el reentelado se descubrió en el reverso del soporte original una inscripción con una antigua atribución a Alonso Cano ${ }^{5}$, circunstancia que es común a otras obras del pintor granadino como la Magdalena penitente ${ }^{6}$ que, procedente de la colección de los condes de Chinchón, ha sido recientemente adquirida por el Ministerio de Cultura para el Museo Nacional del Prado. La prudencia de la citada investigadora y el comprometido estado de conservación de la pintura de la Real Academia de San Fernando ${ }^{7}$, inclinaron a considerarla como de un artista madrileño del siglo XVII del círculo de Alonso Cano [fig. 1]. El presente estudio replantea esa antigua adscripción al maestro granadino en base a algunas evidencias técnicas y un nuevo dibujo que ayuda a explicar mejor su proceso creativo.

En el mismo trabajo donde se daba a conocer esta obra, Arana relacionaba la composición con la estampa de José de Ribera del Sileno ebrio abierta en 1628 [fig. 2], lo que nos daba una fecha postquem para el lienzo. Este es ya un aspecto interesante para tener en cuenta en la reconsideración de su autoría, pues como señaló Pérez Sánchez, Cano fue un artista que usó los grabados y composiciones de Ribera de forma recurrente ${ }^{8}$. Efectivamente, en el proceso creativo de la pintura, la conocida estampa de Ribera resulta decisiva, aunque se adapta sabiamente buscando un efecto de mayor decoro. Así se aprecia en el ropaje que cubre y sirve de apoyo al cuerpo de Baco, que es la solución o el recurso que posibilita ocultar su sexo en sustitución de la hoja de vid que utilizaba el setabense en su grabado. Aunque el cuerpo sigue casi con puntualidad la pose adoptada en la estampa, difiere en cambio la posición de la cabeza que en el grabado está girada hacia la copa en la que un sátiro vierte vino desde una bota. También ha cambiado sustancialmente el porte de los sátiros que le acompañan, reduciéndolos en la pintura a dos criaturas infantiles situadas en un segundo plano a la izquierda. Detrás se coloca el mismo tonel de madera que en la estampa tiene un protagonismo central mientras ahora sirve de marco compositivo lateral.

Pero la variante más profunda $-\mathrm{y}$ por tanto no menor-, está en el paisaje, realizado con una ambientación crepuscular que se ha conseguido gracias a una preparación rojiza de base conjugada con celajes azules de pincelada suelta y ligera. Estos recursos pictóricos resultan bastante similares a los que Alonso Cano empleó en su Cristo de la Humildad de la parroquia de San Ginés; una pintura fechable hacia $1645^{9}$ con fuertes resonancias ticianescas que son las mismas que se advierten en esta pintura y que podrían explicar la atribución asignada a la pintura por parte de Quilliet cuando el lienzo se encontraba en la colección de Godoy. No es aquella la única obra del artista donde se advierten ese tipo de celajes transparentes que dejan adivinar la preparación rojiza, que aparecen también en la Primera labor de Adán y Eva conservada hoy en la Pollock House de Glasgow.

Otro cambio que advertimos en la posición de la cabeza [fig. 3], girada de tres cuartos y en sentido inverso a la estampa donde aparece completamente de perfil, nos adentra en el proceso creativo de esta pintura que podría ayudar a explicar un dibujo que hemos localizado en la Bi-

autor se ignora, altura cuatro pies escasos, por seis ancho, sin marco, número setenta y ocho". En el inventario de 1821 se describe como "Un Sileno reposando en el suelo con una copa en la mano, su autor se ignora". Véase Catálogo, 1821: p. 67 y en Catálogo, 1824: p. 93, n 6 Galería de Esculturas. Sala Octava, que es un pasillo se describe como "Baco desnudo, beodo, y tendido, del tamaño natural". Cfr. Rose, 1983, II: 483. Aunque Rose señala en su ficha que debió entrar en la colección de la Academia en 1816 y que no parecía hallarse allí, sin duda se trata de la pintura que identificó Arana, 2014.

${ }^{5}$ La restauración fue llevada a cabo por Silvia Viana y Judit Gasca en 2014 y en su informe concluyen que la preparación y pigmentos de la obra corresponden con la técnica habitual de Alonso Cano. El cuadro fue reentelado en el siglo XVIII y la intervención hecha en ese momento probablemente produjo pérdidas de pintura importantes y barridos que indudablemente han afectado a la correcta percepción y atribución de la pintura. Véase: https:/www.academiacolecciones.com/buscador.php?q=baco\#\&gid=1\&pid=0413. Consulta 26/01/2020. Agradezco a José María Luzón el conocimiento de este informe.

${ }^{6}$ Urbina, 2013: 63-65.

7 La pintura había sido inventariada como “¿del siglo XVII?”, véase Pérez Sánchez, 1964: p. 42, nº 413.

8 Pérez Sánchez, 1992: 91.

9 Para el replanteamiento de la cronología entre 1640-43 véase Rodríguez Rebollo, 2002: 140-141. 


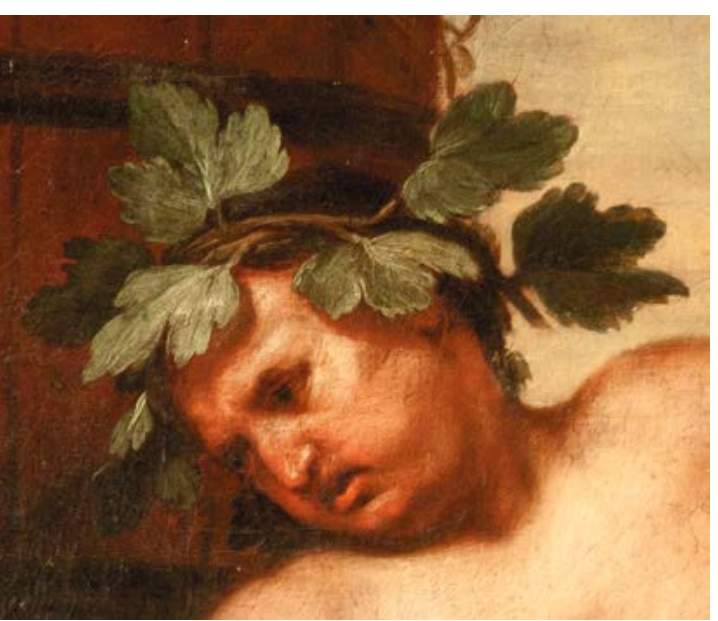

Fig. 3. Alonso Cano (aquí atribuido), detalle de la cabeza del Baco reclinado (1645-1650). Real Academia de Bellas Artes de San Fernando.

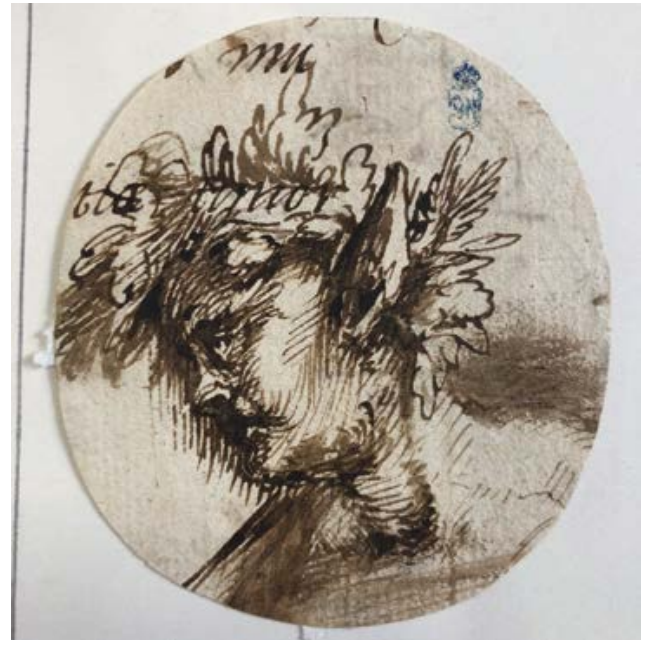

Fig. 4. Alonso Cano (aquí atribuido), Cabeza de sátiro (1645-1650). Biblioteca Nacional de España.

blioteca Nacional de España. Catalogado en las adiciones a Barcia [fig. 4] entre los dibujos italianos del siglo XVI ${ }^{10}$, se trata, sin embargo, de un dibujo característico de Alonso Cano realizado como otros tantos suyos en pluma de caña de tinta parda sobre papel blanco verjurado, y cuyo plumeado explica de forma prodigiosa la metamorfosis que el granadino hace a partir del grabado. Si atendemos a su ejecución gráfica vemos que el perfil del Baco y la cadencia de su cabeza es muy similar a la de la pintura, pero si lo comparamos con la estampa, vemos que de ella el granadino ha seleccionado la oreja del sátiro localizado justo encima de la cabeza de Baco y la ha combinado con los pámpanos y hojas de vid. El plumeado aquí es tan ágil, vibrante y seguro que es absolutamente característico del granadino, tal y como refería Ceán al hablar de sus dibujos: "la mayor parte son de pluma de papel blanco, ayudados con tinta parda, y no son los menos apreciables los más abreviados, porque manifiestan mejor su gran saber, su tino y su talento"11. En efecto, el trabajo de la pluma en forma de líneas curvas que evidencia el rasguño en las hojas de vid es similar al empleado por Cano en las hojas y follajes de algunos de sus dibujos, como por ejemplo en el dibujo del Milagro de los panes y los peces conservado en la University of Michigan Art Museum, o en el Sacrificio de Isaac del Museo del Prado. Por otro lado, los trazos rectos que sirven para configurar los rasgos faciales del perfil de Baco y que se disponen de forma paralela creando el efecto de las sombras, son idénticos a los que se advierten en el dibujo del Desnudo femenino de pie conservado en el gabinete de dibujos y estampas de los Uffizi y en el Triunfo de Apolo de la Biblioteca Nacional ${ }^{12}$.

Creemos que este dibujo es un elemento importante para entender tanto el proceso creativo de esta pintura como para apuntalar su atribución al pintor granadino, uno de los artistas de nuestro barroco más proclives a dejarse llevar por la tradición clásica como recientemente hemos tenido ocasión de señalar ${ }^{13}$. Este rasguño presenta además una inscripción escrita en su parte superior que queremos relacionar con otra autógrafa de Cano que se repite en otro dibujo de tema mitológico que le acabamos de atribuir recientemente: se trata de la Juno ${ }^{14}$ que sirvió como idea

${ }^{10} 68$ x $61 \mathrm{~mm}$. Pluma de tinta parda sobre papel verjurado recortado en formato oval, Biblioteca Nacional de España, Sección de dibujos y estampas: Dib/18/1/296. Como anónimo italiano del siglo XVI, "cabeza de sátiro". Biblioteca Digital Hispánica: http://catalogo.bne.es/uhtbin/cgisirsi/0/x/0/05? searchdata1=binp0000229327. Consulta 06/05/2020.

11 Ceán, 1800, I: 214.

12 Véanse todos estos dibujos en Véliz, 2011: cats. 7, 2, 90,96.

13 Navarrete, 2019: 59-69.

14 Ibidem. 
preparatoria para una de sus obras maestras pintadas en Madrid, muy probablemente con destino a un comitente cortesano. Desgraciadamente no tenemos constancia documental que nos ayude a vincular a Cano ni este Baco ni la citada Juno, aunque sí sabemos que en 1657 ya había realizado temas mitológicos, porque entre los bienes de Margarita Cajés se anotaban como de Cano una "fabula de Ycaro, otro lienço de la fabula de Venus y Cupido y otros dos lienços originales de Cano de Pallas y de Apolo" "15. Algo similar podemos decir del dibujo del Desnudo femenino del Museo del Prado que, como señaló Delfín Rodríguez ${ }^{16}$, muy probablemente se inspiraba en la escultura de la ninfa de la Casa de Pilatos y que, con bastante seguridad, sería preparatorio para una fuente. Creo que es pertinente mencionar aquí un documento que aportó José María Azcárate del pago en abril de 1637 al pintor Juan de Solís de 1.038 reales por "quatro payses y una figura de Baco (sic) y un pedestal de retablo y otras cosas que pintó en la ermita de la Magdalena" en el Buen Retiro ${ }^{17}$, y que el citado autor consideraba un error del pagador, al tratarse realmente de una Magdalena semidesnuda en el desierto y no de un $\mathrm{Baco}^{18}$. Aunque nuestra pintura no puede relacionarse con Solís por su factura, sí nos sirve para justificar que en los ámbitos religiosos también podía haber espacio para pinturas mitológicas, o al menos no resultaba sorprendente. Desgraciadamente los escasos testimonios materiales de pinturas mitológicas que han llegado hasta nosotros han reducido considerablemente los elementos comparativos para este tipo de obras, así como los referentes para poder situar el estatus de las pinturas en su producción y el destino de las mismas. Este dibujo, constituye, pues, un nuevo elemento a tener en cuenta para el estudio de esta pintura de la Academia de San Fernando, y al mismo tiempo para conocer algo mejor los mecanismos compositivos de uno de los artistas más versátiles de nuestra pintura barroca. Un pintor que "tomando ocasión" supo manejar las fuentes como nadie, transformando sabiamente elementos que nos hablan bastante de sus preferencias y, sobre todo, de la metamorfosis final de la imagen, pues "por última, lo que él hacía, ya no era, lo que había visto"19.

\section{BIBLIOGRAFÍA}

Agulló y Cobo, Mercedes (1981): Más noticias sobre pintores madrileños de los siglos XVI al XVIII. Madrid.

Arana Cobos, Itziar (2014): "Una mitología en la Academia". En: Ars Magazine. Revista de Arte y Coleccionismo, 23, pp. 134-135.

Aterido, Ángel (coor.) (2002): Corpus Alonso Cano. Documentos y textos. Madrid: Ministerio de Educación, Cultura y Deporte.

Azcárate, José María (1966): “Anales de la construcción del Buen Retiro”. En: Anales del Instituto de Estudios Madrileños, I, pp. 99-135.

Catálogo de los cuadros, estaturas y bustos que existen en la Academia Nacional de San Fernando en este año de 1821, con expresión de las Salas en que están colocados, números que los distinguen, asuntos que representan y autores que los han ejecutado (1821): Madrid: Ibarra Impresor de Cámara de su Majestad.

Catálogo de las Pinturas y Esculturas que se conservan en la Real Academia de San Fernando (1824): Madrid: Ibarra Impresor de Cámara de su Majestad.

Ceán Bermúdez, Juan Agustín (1800): Diccionario Histórico de los más ilustres profesores de las Bellas Artes en España. Madrid: Real Academia de Bellas Artes de San Fernando.

Morán Turina, Miguel / Portús Pérez, Javier (1997): El Arte de Mirar. La pintura y su público en la España de Velázquez. Madrid: Istmo.

Navarrete Prieto, Benito (2019): “Alonso Cano y la tradición clásica”. En: Ars Magazine. Revista de Arte y coleccionismo, 41, pp. 59-69.

Palomino, Antonio Acisclo (ed.) (1947): El museo pictórico y escala óptica. Madrid: Aguilar.

Pérez Sánchez, Alfonso E. (1964): Inventario de las Pinturas. Madrid: Real Academia de Bellas Artes de San Fernando.

\footnotetext{
15 Agulló, 1981: 35. Aterido, 2002: 367-368.

16 Rodríguez, 1999: 403-430.

${ }_{17}$ Azcárate, 1966, I: 119. Agradezco esta noticia a uno de los pares ciegos que evaluaron este artículo en sus recomendaciones y a la Dra. Beatriz Blasco Esquivias el acceso al artículo en circunstancias no fáciles.

18 Morán-Portús, 1997: 246.

19 Palomino, ed. 1947: 988.
} 
Pérez Sánchez, Alfonso E. (1992): "Ribera y España”. En: Pérez Sánchez, Alfonso E. / Spinosa, Nicola (dirs.). Ribera 1591-1652. Madrid: Museo Nacional del Prado, pp. 79-105.

Rodríguez Rebollo, Ángel (2002): “Cristo de la Clemencia”. En: Alonso Cano. La modernidad del Siglo de Oro español. Madrid: Junta de Andalucía / Fundación Santander Central Hispano, pp. 140-141.

Rodríguez Ruiz, Delfín (1999): "No importa, pues lo iso Cano". Dibujos y pinturas de un arquitecto legendario que sólo quiso ser recordado como escultor". En: AA.VV.: Figuras e imágenes del Barroco. Estudios sobre el barroco español y sobre la obra de Alonso Cano. Madrid: Fundación Argentaria, pp. 403-430.

Rose Wagner, Isadora Joan (1983): Manuel Godoy, patrón de las artes y coleccionista. T. II. Madrid: Universidad Complutense de Madrid.

Urbina, José Antonio de (2013): “...Y nuevas incorporaciones al catálogo de El Racionero”. En: Ars Magazine, 20, octubre-diciembre, 2013, pp. 63-67.

Véliz, Zahira (2011): Alonso Cano (1601-1667). Dibujos. Catálogo razonado. Santander: Fundación Botín.

Fecha de recepción: 24-X-2019

Fecha de aceptación:04-V-2020 